\title{
$B R A F$ and PIK3CA genes are somatically mutated in hepatocellular carcinoma among patients from South Italy
}

\author{
M Colombino ${ }^{1}$, P Sperlongano ${ }^{2}, \mathrm{~F}$ Izzo $^{3}, \mathrm{~F}$ Tatangelo ${ }^{3}$, G Botti ${ }^{3}$, A Lombardi ${ }^{4}, \mathrm{M}$ Accardo ${ }^{5}$, L Tarantino ${ }^{6}$, I Sordelli ${ }^{2}$, M Agresti ${ }^{2}$, \\ A Abbruzzese ${ }^{4}$, M Caraglia $^{*, 4}$ and G Palmieri ${ }^{*, 1}$
}

Poor data have been previously reported about the mutation rates in K-RAS, BRAF, and PIK3CA genes among patients with hepatocellular carcinoma (HCC). Here we further elucidated the role of these genes in pathogenesis of primary hepatic malignancies. Archival tumour tissue from $65 \mathrm{HCC}$ patients originating from South Italy were screened for mutations in these candidate genes by direct sequencing. Overall, oncogenic mutations were detected in $15(23 \%)$ patients for BRAF gene, $18(28 \%)$ for PIK3CA gene, and $1(2 \%)$ for $K-R A S$ gene. Using statistical analysis, BRAF mutations were significantly correlated with the presence of either multiple HCC nodules $(P=0.021)$ or higher proliferation rates $(P=0.034)$. Although further extensive screenings are awaited in HCC patients among different populations, our findings clearly indicated that mutational activation of both BRAF and PIK3CA genes does contribute to hepatocellular tumorigenesis at somatic level in Southern Italian population. Cell Death and Disease (2012) 3, e259; doi:10.1038/cddis.2011.136; published online 19 January 2012

Subject Category: Cancer

Hepatocellular carcinoma (HCC) is among the most common malignancies worldwide, with approximately more than 500000 new patients diagnosed each year; however, significant regional differences in the incidence of $\mathrm{HCC}$ are observed because of the frequency of the different aetiological factors involved in HCC development. ${ }^{1}$

Despite major efforts to improve diagnosis and treatment of HCC, therapeutic options remain limited; treatment options depend on the stage of the disease and the extent of liver dysfunction and cirrhosis. ${ }^{2}$ Therefore, targeting the key-role genes and pathways have increasingly gained attention. Actually, molecular mechanisms leading to malignant transformation of hepatocytes as well as development and progression of HCC still remain largely unclear. The mitogen-activated protein kinase (MAPK) pathway (including the cascade of RAS, BRAF, MEK1/2, and extracellular-signal-regulated kinase (ERK)1/2 proteins) has emerged as a major signalling cascade, involved in the control of cell growth, proliferation, and migration in majority of the cancers. Recently, sorafenib, an oral multikinase inhibitor targeting BRAF among other cellular kinases, has been demonstrated to be effective in $\mathrm{HCC}^{3}$

Besides a well-documented overexpression of RAS in human $\mathrm{HCC},{ }^{4}$ activating mutations of the RAS oncogenes (particularly those affecting the K-RAS gene) have been classified as rare events during hepatocarcinogenesis. ${ }^{5}$ On the other hand, RAS mutations have been frequently identified in HCC induced by various chemical agents in animals. ${ }^{6}$ From the same signalling cascade, somatic mutations of the BRAF serine/threonine kinase gene have been reported at various frequencies among different types of human cancers. ${ }^{7}$ Similar to the RAS alterations, BRAF mutations seem to poorly participate in the pathogenesis of human HCC. $^{8}$ However, a clear statement about the prevalence of both RAS and BRAF mutations in $\mathrm{HCC}$ is yet to be definitely assessed, and differences may exist because of the geographical origins of the patients' populations and probably to the different aetiological factors that have been involved in hepatocellular carcinogenesis.

A higher amount of reports has been published revealing that the phosphoinositide-3-kinase-catalytic-alpha (PIK3CA) gene may be somatically mutated in several types of human cancer, including HCC. ${ }^{9-10}$ In particular, PIK3CA is an effector of the phosphatase and tensin homologue (PTEN)-AKT pathway, which is involved in the inhibition of focal adhesion formation, cell spreading, and migration, as well as in the inhibition of growth factor-stimulated MAPK signalling (alterations in the RAS-BRAF pathway are frequently associated with the PTEN-PIK3CA impairments). ${ }^{11}$

In the present study, we analysed the mutational status of the K-RAS, BRAF, and PIK3CA genes in a series of HCC tissues from patients originating from South Italy, to further elucidate the possible role of these genes in primary hepatic malignancies.

\footnotetext{
${ }^{1}$ Institute of Biomolecular Chemistry, National Research Council (CNR), Sassari, Italy; ${ }^{2}$ Department of Surgery, Second University of Naples, Naples, Italy; ${ }^{3}$ National Cancer Institute 'Fondazione G Pascale', Naples, Italy; ${ }^{4}$ Department of Biochemistry and Biophysics, Second University of Naples, Naples, Italy; ${ }^{5}$ Department of Public and Preventive Medicine, Second University of Naples, Naples, Italy and ${ }^{6}$ Department of Surgery, 'S Giovanni di Dio' Hospital, Frattamaggiore, Naples, Italy ${ }^{*}$ Corresponding authors: M Caraglia, Department of Biochemistry and Biophysics, Second University of Naples, Via Costantinopoli, 1680138 Naples, Italy. Tel: + 39081 5665871; Fax: + 39081 5665863; E-mail: michele.caraglia@unina2.it or michele.caraglia@alice.it or G Palmieri, Institute of Biomolecular Chemistry, National Research Council (CNR), Sassari, Italy. Tel: + 39079 2841201/2; Fax: + 39 079 2841299; E-mail: gpalmieri@yahoo.com

Keywords: hepatocellular carcinoma; cancer genes; mutation analysis; patients' molecular classification

Abbreviations: HCC, hepatocellular carcinoma; MAPK, mitogen-activated protein kinase; ERK, extracellular-signal-regulated kinase; PIK3CA, phosphoinositide-3kinase-catalytic-alpha; PTEN, phosphatase and tensin homologue

Received 15.7.11; revised 22.9.11; accepted 16.11.11; Edited by G Melino
} 


\section{Results}

Genomic DNA from 65 consecutively collected HCC patients was screened for somatic mutations in BRAF, K-RAS, and $P I K 3 C A$ genes. The study population consisted of $48(74 \%)$ males and 17 (26\%) females, with a median age of 69 years (range, 58-81 years). Histological patterns included trabecular (41 cases; $63 \%)$, solid $(21 ; 32 \%)$, mixed $(1 ; 2 \%)$, and unclassified $(2 ; 3 \%)$ types.

The full coding sequence and intron-exon junctions of the candidate exons (see Materials and Methods) were assessed in such different HCC samples. Figure 1 shows the nucleotide sequences for the somatic mutations identified in our series. Overall, mutations were detected in 15 (23\%) HCCs for the BRAF gene, 18 (28\%) cases for the PIK3CA gene, and $1(2 \%)$ patient for the K-RAS gene (the rates of each specific mutation are shown at bottom of Figure 1). Four cases presented co-existence of BRAF and PIK $3 C A$ mutations; altogether, $30 / 65$ (46\%) patients carried a somatic mutation in at least one of the above-mentioned genes. All BRAF mutations were represented by the most common substitution of valine by glutamic acid at position 600 (V600E; Figure 1). None of the sequence changes identified was present in normal adjacent tissues from the same HCC cases, indicating that these variants are tumour-specific and somatically acquired mutations.

Using statistical tests, BRAF and PIK3CA mutations were evaluated for association with several pathological parameters: sex, age at diagnosis, tumour grading, pathological tumour size (pT; according to the TNM classification ${ }^{13}$ ), total number of tumour lesions within hepatic parenchyma (single or multiple HCC nodules), and rate of proliferations (as inferred by the levels of tumour mitosis; Table 1). In our series, the only significant correlation was found between the occurrence of BRAF mutations and the presence of either multiple HCC nodules $(P=0.021)$ or higher proliferation rates $(P=0.034 ;$ Table 1$)$. No significant association was observed between the BRAF or PIK3CA mutations and other parameters (though a trend for BRAF mutations to be associated with an older age of onset, a higher tumour grade, and a larger
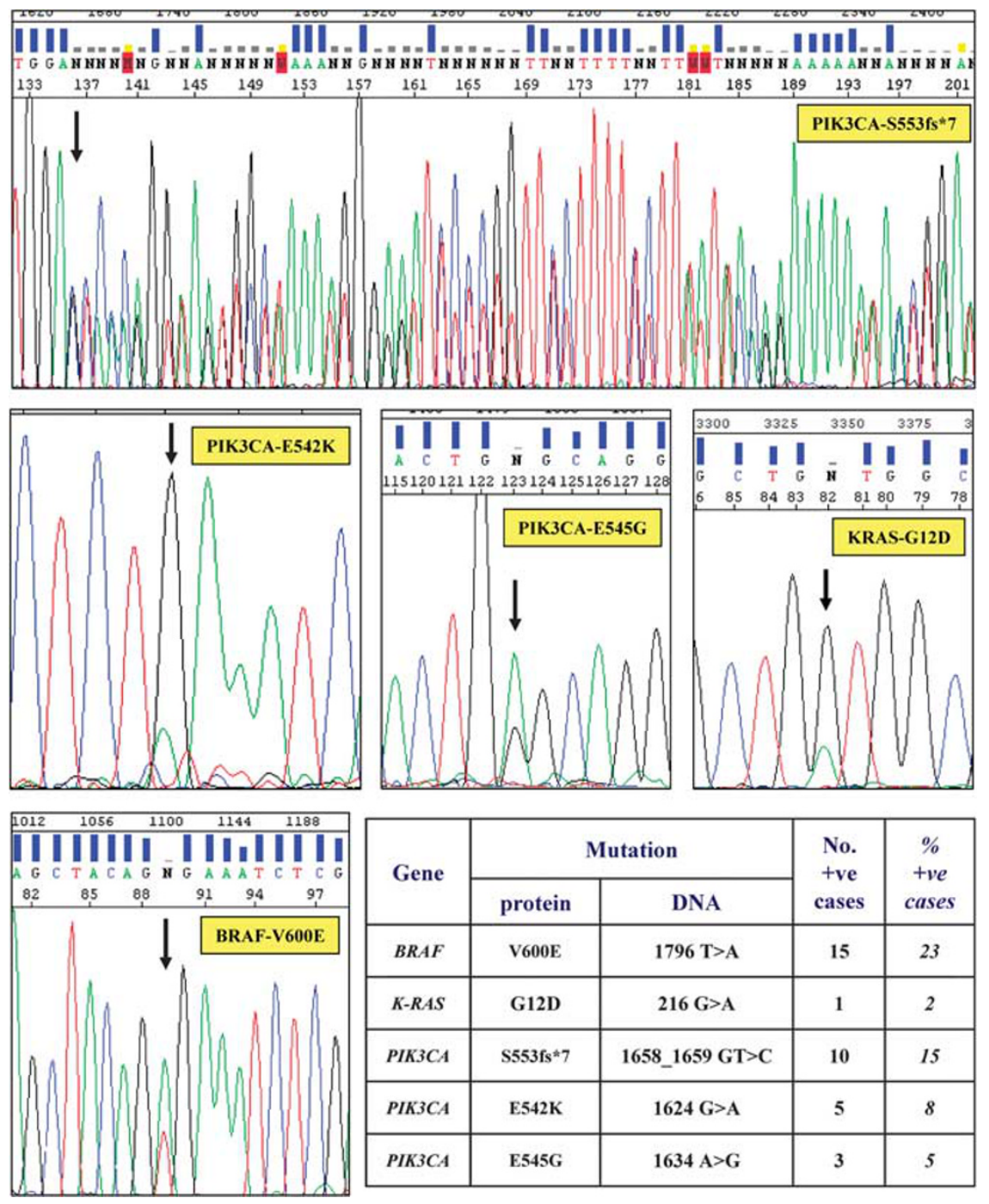

\begin{tabular}{|c|c|c|c|c|}
\hline \multirow{2}{*}{ Gene } & \multicolumn{2}{|c|}{ Mutation } & \multirow{2}{*}{$\begin{array}{c}\text { No. } \\
+v e \\
\text { cases }\end{array}$} & $\begin{array}{c}\% \\
+v e \\
\text { cases }\end{array}$ \\
\cline { 2 - 3 } & protein & DNA & 15 & 23 \\
\hline BRAF & V600E & $1796 \mathrm{~T}>\mathrm{A}$ & 1 & 2 \\
\hline K-RAS & G12D & $216 \mathrm{G}>\mathrm{A}$ & 10 & 15 \\
\hline PIK3CA & S553f^ & $1658 \_1659 \mathrm{GT}>\mathrm{C}$ & 5 & 8 \\
\hline PIK3CA & E542K & $1624 \mathrm{G}>\mathrm{A}$ & 3 & 5 \\
\hline PIK3CA & E545G & $1634 \mathrm{~A}>\mathrm{G}$ & & \\
\hline
\end{tabular}

Figure 1 Sequencing results for identified somatic mutations. Electropherograms show the nucleotide sequences of the genomic DNA from positive HCC samples; arrows indicate the mutation position within the sequence. Bottom right: prevalence of all mutations, designed for both DNA and amino acid changes 
Table 1 Distribution of mutations according to the characteristics of $\mathrm{HCC}$ patients

\begin{tabular}{|c|c|c|c|c|c|c|}
\hline \multirow[b]{2}{*}{$\begin{array}{l}\text { Characteristics } \\
\text { (patients) }\end{array}$} & \multicolumn{3}{|c|}{ BRAF } & \multicolumn{3}{|c|}{ PIK3CA } \\
\hline & $\begin{array}{l}\text { Mutated } \\
\text { cases }\end{array}$ & $\%$ & $\boldsymbol{P}$ & $\begin{array}{l}\text { Mutated } \\
\text { cases }\end{array}$ & $\%$ & $\boldsymbol{P}$ \\
\hline \multicolumn{7}{|l|}{ Sex } \\
\hline $\begin{array}{l}\text { Male }(N=48) \\
\text { Female }(N=17)\end{array}$ & $\begin{array}{c}11 \\
4\end{array}$ & $\begin{array}{l}23 \\
24\end{array}$ & 0.972 & $\begin{array}{c}13 \\
5\end{array}$ & $\begin{array}{l}27 \\
29\end{array}$ & 0.875 \\
\hline \multicolumn{7}{|l|}{ Age } \\
\hline $\begin{array}{l}\leq 60(N=13) \\
>60(N=52)\end{array}$ & $\begin{array}{c}2 \\
13\end{array}$ & $\begin{array}{l}15 \\
25\end{array}$ & 0.219 & $\begin{array}{c}4 \\
14\end{array}$ & $\begin{array}{l}31 \\
27\end{array}$ & 0.8 \\
\hline \multicolumn{7}{|l|}{ Grading } \\
\hline $\begin{array}{l}\mathrm{G} 2(N=52) \\
\mathrm{G} 3(N=13)\end{array}$ & $\begin{array}{c}11 \\
4\end{array}$ & $\begin{array}{l}21 \\
31\end{array}$ & 0.211 & $\begin{array}{c}15 \\
3\end{array}$ & $\begin{array}{l}29 \\
23\end{array}$ & 0.4 \\
\hline \multicolumn{7}{|l|}{$p T$} \\
\hline $\begin{array}{l}\text { pT1 }(N=20) \\
\text { pT2 }(N=34) \\
\text { pT3 }(N=11)\end{array}$ & $\begin{array}{l}4 \\
7 \\
4\end{array}$ & $\begin{array}{l}20 \\
21 \\
36\end{array}$ & 0.187 & $\begin{array}{l}8 \\
8 \\
2\end{array}$ & $\begin{array}{l}40 \\
24 \\
18\end{array}$ & 0.1 \\
\hline \multicolumn{7}{|l|}{ No. of tumour sites } \\
\hline $\begin{array}{l}\text { Single }(N=43) \\
\text { Multiple }(N=22)\end{array}$ & $\begin{array}{c}4 \\
11\end{array}$ & $\begin{array}{c}9 \\
50\end{array}$ & 0.021 & $\begin{array}{c}13 \\
5\end{array}$ & $\begin{array}{l}30 \\
23\end{array}$ & 0.353 \\
\hline \multicolumn{7}{|c|}{ No. of tumour mitoses } \\
\hline $\begin{array}{l}\text { Low }(N=47) \\
\text { High }(N=18)\end{array}$ & $\begin{array}{l}6 \\
9\end{array}$ & $\begin{array}{l}13 \\
50\end{array}$ & 0.034 & $\begin{array}{c}14 \\
4\end{array}$ & $\begin{array}{l}30 \\
22\end{array}$ & 0.32 \\
\hline
\end{tabular}

Abbreviations: HCC, hepatocellular carcinoma; PIK3CA, phosphoinositide-3kinase-catalytic-alpha

primary tumour, as well as for PIK3CA mutations to be conversely associated with earlier primary HCC was inferred; Table 1).

\section{Discussion}

In this study, we examined the frequency of activating mutations of the BRAF, K-RAS, and PIK3CA genes in a series of 65 human HCC samples from patients originating from South Italy. In our series, K-RAS mutations were quite absent (only one patient presented an oncogenic mutation in this gene) confirming data from literature, indicating that mutations in K-RAS are rare and likely not a key event in hepatocarcinogenesis. On the other hand, a higher-thanexpected prevalence of somatic mutations was observed for the BRAF gene $(15 / 65 ; 23 \%)$. In the unique previous study on this issue, no BRAF mutation was indeed observed in a small subset of human HCC patients. ${ }^{8}$ One could speculate that the higher frequency detected in our series may be somehow due to the patients' origin or, in other words, to the different 'genetic background' of populations from the two studies. Moreover, it cannot be excluded that different aetiological factors could be involved in the HCC development among different populations, and therefore, different mechanisms of transformation could occur. The most common mutation in $B R A F$ gene (nearly, $90 \%$ of cases) is a substitution of valine with glutamic acid at position 600 (V600E). ${ }^{7}$ This mutation, which is present in exon 15 within the kinase domain, represented the only variant identified in our HCC tissues.
Controversial data have been published about the PIK $3 C A$ mutation rates, ranging from none ${ }^{14}$ to one-third ${ }^{9-10}$ of the HCC cases presenting a mutated PIK3CA (interestingly, the two main contrasting reports are based on patients from the Eastern populations). In the present study, mutations were detected in quite a high fraction of the HCC tissues (18/65; 28\%).

Overall, our study provides clear indications that mutational activation of both the BRAF and PIK3CA genes indeed participates to hepatocellular tumorigenesis at the somatic level in the southern Italian population. From the functional point of view, BRAF and RAS are members of the MAPK (RAS-BRAF-MEK-ERK) pathway, which mediates cellular response to growth signals. In particular, activated BRAF or RAS (mutation in encoding two genes have been demonstrated to be mutually exclusive ${ }^{15-16}$ ) participate in the sustained induction of cell cycle progression. More in general, the MAPK and the PIK3CA signalling pathways both have a key role in cell proliferation and survival; their oncogenic activation deeply contributes to pathogenesis of different solid tumours, including HCC.

Nevertheless, BRAF and PIK3CA mutations were more or less equally distributed among the different patients' subsets in our series, and no statistically significant correlation with sex, onset age, histological tumour type, primary tumour size, and grading were observed. However, patients with HCC carrying a mutated $B R A F$ are more likely to significantly present with multifocal or more aggressive disease (see Table 1).

More extensive screenings should be carried out to confirm the prevalence and distribution of BRAF- and PIK3CAactivating mutations in $\mathrm{HCC}$ among different populations. Actually, this need is particularly strong, as inhibition of the RAS-BRAF-MEK-ERK pathway may be an important new therapeutic strategy in HCC. More specifically, BRAF mutations have become a favoured target for the treatment of advanced HCC, because of the clinical development of the RAF-kinase inhibitor sorafenib that has found indication in the treatment of HCC in the United States, Europe, and Asia. ${ }^{17-18}$ The different response rates observed in the clinical trials that led to the registration of sorafenib in HCC treatment could be, on the basis of our data, not only due to the different status of accompanying cirrhotic disease, but also to a different distribution of candidate gene mutations. Therefore, it should be interesting to correlate such a mutational status to the clinical responsiveness. In this view, we have recently demonstrated that the decrease of the phosphorylation of downstream ERK (a surrogate marker of the RAF kinase activity) is a predictive marker of response to a combination between sorafenib and octreotide in advanced HCC. ${ }^{19-20}$ Trying to point out such issues, we already started a new study in which HCC patients are being prospectively enrolled and adequately followed-up, with registration of all the main clinical information (type of treatment(s), clinical behaviour of the disease, date of last control or death) and inclusion of the expression analysis by immunohistochemistry for several effectors of the BRAF-PI3K pathways (K-RAS, MEK, phospoERK, PTEN, AKT).

Finally, our findings may provide new therapeutic options for the subset of patients carrying the ${ }^{\mathrm{V} 600 \mathrm{E}}$ BRAF mutations, 
as selective and potent BRAF inhibitors have been recently developed. ${ }^{21-23}$ Vemurafenib, a specific inhibitor of the BRAF $^{\mathrm{V} 600 \mathrm{E}}$ variant, has indeed showed a very promising activity in patients positive for such a mutation. ${ }^{23}$ Nevertheless, the identification of a mutated PIK3CA gene, which is becoming a promising target for newly discovered anticancer drugs, ${ }^{24}$ potentially gives an additional opportunity for identifying HCC patients who may benefit from alternative treatment strategies. One could hypothesize that new therapies, aimed at blocking the key molecular pathways, which are differently altered during hepatocellular tumorigenesis, in combination with the molecular classification of such distinct patients' subsets may become the gold standard for future treatment approaches in the HCC disease.

\section{Materials and Methods}

Samples. A total of 65 patients with histologically proven diagnosis of $\mathrm{HCC}$ were included into the study. For tumour typing, the classification according the AJCC/ UICC guidelines was adopted. ${ }^{12}$ Tumour size was based on the largest dimension of the tumour specimen. Multiple lesions were defined by the presence of two or more nodules of tumours including intrahepatic metastasis.

Neoplastic tissue samples were obtained from pathological archives using appropriate informed consent procedures. The study was reviewed and approved by the ethical review board of the University of Sassari.

Mutation analysis. For mutation analysis, genomic DNA was isolated from tumour tissue samples, using standard methods. Tumour tissues were estimated to contain at least $70 \%$ neoplastic cells by light microscopy.

The complete coding sequences and intron-exon boundaries of the K-RAS exons 2-3, BRAF exon 15, and PIK3CA exons 9-20, were screened for mutations by direct sequencing, using an automated fluorescence-based cycle sequencer (ABIPRISM3100, Applied Biosystems, Foster City, CA, USA). Primer sequences were as reported in Genome DataBase (http://www.gdb.org).

Statistical analysis. Fisher's exact test and $\chi^{2}$-test were used to evaluate possible associations between covariates (mutated and wild-type genotypes) and clinical or pathological parameters. Variables were also evaluated for independent correlations by Cox regression analysis. Statistical comparisons were performed using the SPSS statistical software package, version 15.0 (SPSS Inc., Chicago, IL, USA). All tests were two-tailed and $P$-values of less than 0.05 were considered to be statistically significant.

\section{Conflict of Interest}

The authors declare no conflict of interest.

Acknowledgements. We are grateful to the patients for their important contribution to this study. We like to thank Dr Mario Budroni for the statistical analyses. This work was supported by the Ricerca Finalizzata Ministero della Salute and Sardinian Regional Government (Regione Autonoma Sardegna). AB was supported by a grant from MIUR (PRIN 2008).

\section{Author Contributions}

MC carried out mutation analysis; PC performed the research; FI participated in patients' collection; FT and GB performed pathological review; $\mathrm{AL}$ and $\mathrm{MA}$ contributed to data analysis; LT participated in patients' collection; IS and MA participated in performing the research; AA contributed to the study design; MC participated in both designing the research study and writing the paper; GP wrote the paper

1. Parkin DM, Bray F, Ferlay J, Pisani P. Global cancer statistics. CA Cancer J Clin 2005; 55 : 74-108.

2. Llovet JM. Updated treatment approach to hepatocellular carcinoma. J Gastroenterol 2005; 40: 225-235.

3. Llovet JM, Ricci S, Mazzaferro V, Hilgard P, Gane E, Blanc JF et al. Sorafenib in advanced hepatocellular carcinoma. N Engl J Med 2008; 359: 378-390.

4. Bose S, Sakhuja P, Bezawada L, Agarwal AK, Kazim SN, Khan LA et al. Hepatocellular carcinoma with persistent hepatitis $B$ virus infection shows unusual downregulation of Ras expression and differential response to Ras mediated signaling. J Gastroenterol Hepatol 2011; 26: 135-144.

5. Teufel A, Staib F, Kanzler S, Weinmann A, Schulze-Bergkamen H, Galle PR. Genetics of hepatocellular carcinoma. World J Gastroenterol 2007; 13: 2271-2282.

6. Bai F, Nakanishi Y, Takayama K, Pei XH, Inoue K, Harada T et al. Codon 64 of K-ras gene mutation pattern in hepatocellular carcinomas induced by bleomycin and 1-nitropyrene in A/J mice. Teratog Carcinog Mutagen 2003 (Suppl 1): 161-170.

7. Davies H, Bignell G, Cox C, Stephens P, Edkins S, Clegg S et al. Mutations of the BRAF gene in human cancer. Nature 2002; 417: 949-954.

8. Tannapfel A, Sommerer F, Benicke M, Katalinic A, Uhlmann D, Witzigmann $\mathrm{H}$ et al. Mutations of the BRAF gene in cholangiocarcinoma but not in hepatocellular carcinoma. Gut 2003; 52: 706-712.

9. Lee JW, Soung YH, Kim SY, Lee HW, Park WS, Nam SW et al. PIK3CA gene is frequently mutated in breast carcinomas and hepatocellular carcinomas. Oncogene 2005; 24: $1477-1480$.

10. Boyault S, Rickman DS, de Reyniès A, Balabaud C, Rebouissou S, Jeannot E et al. Transcriptome classification of $\mathrm{HCC}$ is related to gene alterations and to new therapeutic targets. Hepatology 2007; 45: 42-52.

11. Arcaro A, Guerreiro AS. The phosphoinositide 3-kinase pathway in human cancer: genetic alterations and therapeutic implications. Curr Genomics 2007; 8: 271-306.

12. Greene FL, Page DL, Fleming ID (eds) American Joint Committee on Cancer Staging Manual 6th edn, Springer: Philadelphia, 2002.

13. Sobin LH, Mary K, Gospodarowicz MK, Christian Wittekind C (eds). TNM Classification of Malignant Tumours 7th edn, Wiley Blackwell: New York, USA, 2009.

14. Tanaka Y, Kanai F, Tada M, Asaoka Y, Guleng B, Jazag A et al. Absence of PIK3CA hotspot mutations in hepatocellular carcinoma in Japanese patients. Oncogene 2006; 25: 2950-2952.

15. Sensi M, Nicolini G, Petti C, Bersani I, Lozupone F, Molla A et al. Mutually exclusive NRASQ61R and BRAFV600E mutations at the single-cell level in the same human melanoma. Oncogene 2006; 25: 3357-3364.

16. Gray-Schopfer V, Wellbrock $C$, Marais R. Melanoma biology and new targeted therapy. Nature 2007; 445: 851-857.

17. Abou-Alfa GK, Schwartz L, Ricci S, Amadori D, Santoro A, Figer A et al. Phase II study of sorafenib in patients with advanced hepatocellular carcinoma. J Clin Oncol 2006; 24: 4293-4300.

18. Yau T, Chan P, Epstein R, Poon RT. Management of advanced hepatocellular carcinoma in the era of targeted therapy. Liver Int 2009; 291: 10-17.

19. Del Prete S, Montella L, Caraglia M, Maiorino L, Cennamo G, Montesarchio V et al. Sorafenib plus octreotide is an effective and safe treatment in advanced hepatocellular carcinoma: multicenter phase II So.LAR. study. Cancer Chemother Pharmacol 2009; 645: 863-866.

20. Caraglia M, Giuberti G, Marra M, Addeo R, Montella L, Murolo M et al. Oxidative stress and ERK $1 / 2$ phosphorylation as predictors of outcome in hepatocellular carcinoma patients treated with sorafenib plus octreotide LAR. Cell Death Dis 2011; 2: e150.

21. Bollag G, Hirth P, Tsai J, Zhang J, Ibrahim PN, Cho $\mathrm{H}$ et al. Clinical efficacy of a RAF inhibitor needs broad target blockade in BRAF-mutant melanoma. Nature 2010; 467: 596-599.

22. Flaherty KT, Puzanov I, Kim KB, Ribas A, McArthur GA, Sosman JA et al. Inhibition of mutated, activated BRAF in metastatic melanoma. N Engl J Med 2010; 363: 809-819.

23. Chapman PB, Hauschild A, Robert $\mathrm{C}$, Haanen JB, Ascierto $\mathrm{P}$, Larkin $\mathrm{J}$ et al. Improved survival with vemurafenib in melanoma with BRAF V600E mutation. N Engl J Med 2011; 364: 2507-2516.

24. Garcia-Echeverria C, Sellers WR. Drug discovery approaches targeting the PI3K/Akt pathway in cancer. Oncogene 2008; 27: 5511-5526.

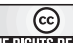

OMERIIITS

published by Nature Publishing Group. This work is licensed under the Creative Commons Attribution-Noncommercial-No Derivative Works 3.0 Unported License. To view a copy of this license, visit http://creativecommons.org/licenses/by-nc-nd/3.0/ 